\title{
Téoros
}

Revue de recherche en tourisme

\section{Réflexions sur Québec et le tourisme}

\section{Jean-Paul L'Allier}

Volume 12, numéro 1, mars 1993

Québec, capitale et région touristiques

URI : https://id.erudit.org/iderudit/1078205ar

DOI : https://doi.org/10.7202/1078205ar

Aller au sommaire du numéro

Éditeur(s)

Université du Québec à Montréal

ISSN

0712-8657 (imprimé)

1923-2705 (numérique)

Découvrir la revue

Citer cet article

L’Allier, J.-P. (1993). Réflexions sur Québec et le tourisme. Téoros, 12(1), 51-52. https://doi.org/10.7202/1078205ar d'utilisation que vous pouvez consulter en ligne.

https://apropos.erudit.org/fr/usagers/politique-dutilisation/ 


\title{
Réflexions sur Québec et le tourisme
}

\author{
Jean-Paul L'Allier*
}

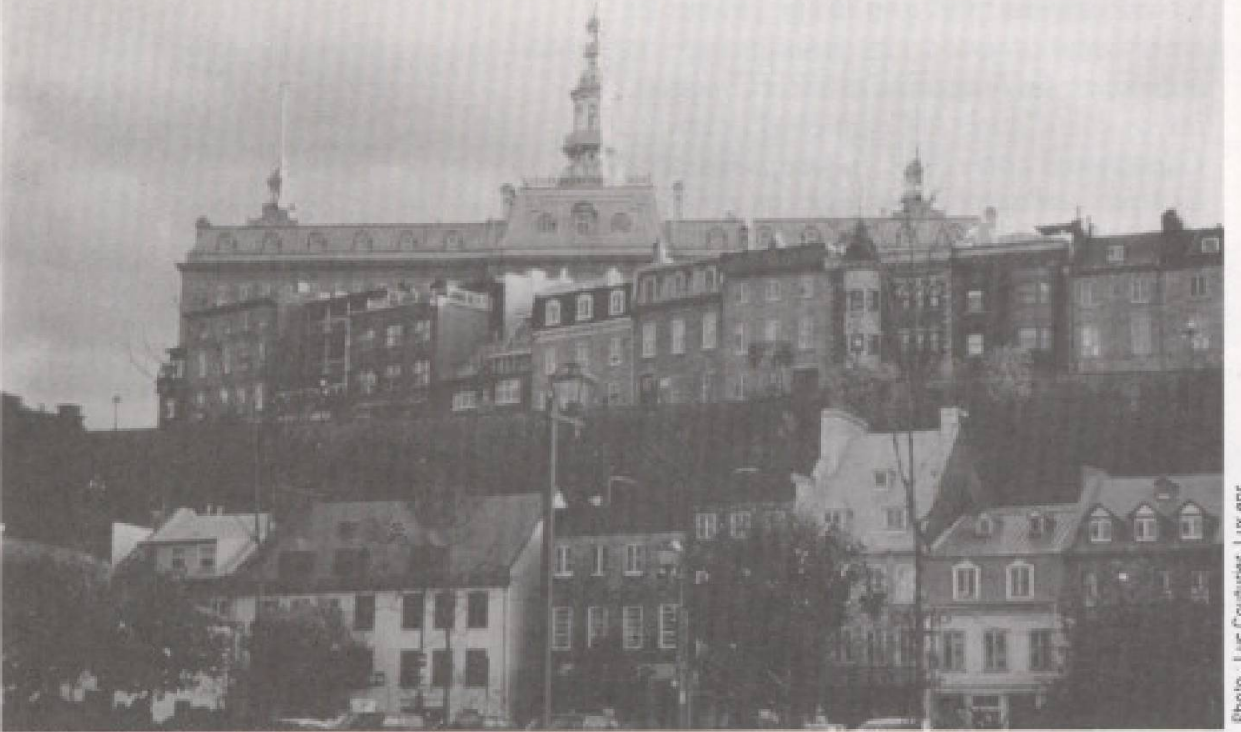

- Quebec séduit de multiples façons mais essertiellement pour ce qu' elle est' profondément....

Le sujet a l'air facile mais c'est, je dois me rendre à l'évidence, $l^{\top}$ un des plus difficiles à aborder quand on est amoureux de sa ville. Québec est une ville touristique, il faut y venir pour le voir mais de toute évidence, elle est d'abord beaucoup d'autres choses. Au coeur de notre économie, dans tous les discours politiques sur le développement, le tourisme est souventperçu, à Québec, comme l"industrie maîtresse, celle de qui on attend tout. Dès lors, on parle en chiffres, en statistiques, en nuitées, en places de parking et en chambres d'hôttels.

Tout cela est vrai et le tourisme est effectivement une des principales sources de notre vie économique et certainement la plus importante productrice de devises étrangères.

Ceux qui vendent les voyages et les sćjours le savent et ce n"est pas pour rien que partout, jusqu'au fond des boutiques de tourisme à Tokyo, on voit laphotodu Château Frontenac autant que celle des Chutes du Niagara ou de la Tour Eiffel.

Monsieur Jean-Paul L'Allier est maire de la ville de Quebec.
Développer une industrie, c'est chercher, garder et amplifier des clientèles. C'est convaincre que parmi la multitude de choix qui s"offrent, un séjourà Québecrépondramieux. aux attentes et aux désirs multiples de ceux qui paient pour voyager.

Il faut donc connaître ses clientèles, celles que l'on a, pour les conserver, et celles que l'on souhaite, pour les attirer. Il faut savoir écouter les commentaires et les critiques de ceux qui viennent et de ceux qui voudraient venir. Il faut chercher, dans tout ce que l'on a àoffrir, ce qui a le plus de chance de séduire par des qualités vraies et de répondre aux attentes sans tricherie ni tromperie.

Un village à la Walt Disney est toujours une destination touristique non équivoque. C'est un produit conçu exclusivement pour satisfaire des besoins pré-identifiés. MaisQuébec $n$ ' est pas un village a la Walt Disney et ce que nous avons à offrir ne doit pas ressembler à ce produit fait sur mesure. Ceux et cellesquiont voyage le savent: de toutes les villes avec lesquelles on est en contact dans une vie, bien peu finalement nous laissent une image et une impression forte pour qu' on rêve d'y retoumer aux moments qui nous sont les plus chers.
Je garde un souvenir inoubliable de mes multiples séjours à Bruges, en Belgique, d'un trop court voyage a Vienne et d'une vacance familiale dans un tout petit village d'une île greoque. J'aurais cependant beaucoup de peine à vous nommer dix des multiples villes américaines ou européennes que j'ai eu l'occasion de voir dans ma vie et où j'aurais vraiment envie de retoumer.

Québec, ville touristique, c'est d'abord une population qui offre généreusement au visiteur età sa famille une partie, pour ne pas dire l'excédent, de sa propre qualité de vie. Un cadre physique exceptionnel, un coeur de ville conçu et bâti quelques siècles avant l'existence de l'automobile, un climat capricieux mais franc et généreux selon les saisons, un contact facile avec les gens, des rues propres et securitaires, une restauration accessible etsouvent de haute qualitédans un contexte oùse multiplient pourtant leschaînes multinationales du prêt-à-manger.

A vivre le quotidien d'une ville, on en arrive à oublier sabeauté, son charme, son caractère etsa force d'attraction, A partager quotidiennement des visiteurs venus de partout et a entendre leurs commentaires on garde conscience du privilège que nous avons de vivre dans un milieu qui a tant à offrir à ceux qui le choisissent autant qu'à ceux qui $\mathrm{y}$ viennent en touristes, congressistes ou visiteurs d'affaires.

Ceux qui viventde l' industrie touristique ont donc tout intếțà protéger comme laprunelle de leurs yeux cette richesse exceptionnelle que représente Québec et ses environs, sans céder a la tentation toujours présente et quelquefois vérifiable d'exploiter par l'arnaque le visiteur trop naif ou coincé dans un des grands événements qu'il n'avait pas prévu. Partager Québec, c'est choisir attentivement chacune des forces d'attraction qui attirent dejà ceux qui y viennent, c'est développer des produits authentiques, mettant en valeur autant le patrimoine esthétique que les sites naturels et les services de restauration et d'hôtellerie. Une promotion trompeuse attirera quelques-uns mais le gain immédiat n'est rien à côté des pertes qu'engendre le départ d'un visiteur frustré, leuré ou brimé. 
Accueillir les gens, c'est d'abordles informer avec précision, au bon moment et complètement, sur les choix qui s' offrent à eux et sur la meilleure façon de vivre notre ville pour le temps qu'ils y passeront. C'est tout faire pour qu'au terme de leur séjour, en plus de jouir de la satisfaction qu'ils en attendaient, ils aient envie d'en parler longtemps et de revenir souvent. Voilà pourquoi je travaille a ce que ma ville devienne celle où, de toutes les villes canadiennes, on traite le mieux nos citoyens autant que nos touristes en matière de circulation, de signalisation routière, de stationnement et d'information, un défi de taille dans un tissu urbain où les rues ont été conçues pour les chevaux et les calèches.

Ceux qui offrent une ville au tourisme ont tout intérêt à bien connaître leur clientèle pour pouvoir la présenter, cette ville, sous l'angle susceptible de les séduire. Au Japon, Québec est vendue comme une destination de voyage de noces exotique, au même titre qu' Hawaii et les Chutes du Niagara. C'est le Château Frontenac plutôt que la ville que les Japonais perçoivent comme motivation suffisante à un voyage qui coûte environ $6000 \$$ pour deux personnes et pour dix jours. $\AA$ l'occasion de ce séjour, les promenades dans Québecne sont passans leur rappelercertaines rues de Kyoto, malgré la distance et le dépaysement culturel. Lorsque les gens de Mobile, Alabama, viennent au Camaval, ils refont le voyage des fondateurs de leur ville, une sorte de pèlerinage historique à l'occasion de notre fête de l'hiver. Les milliers de Français qui, chaque année maintenant, viennent chez nous, ont pour la plupart déjà été en contact avec des Québécois et n'en sont même plus à leur premier voyage. Le mode de vie, l'accueil et le dépaysement relatif les attirent mais les grands espaces et les contacts avec la nature, plus qu'on ne l'imagine, sont à l'origine de leur choix.

Une ville doit donc séduire pour gagner et garder sa place sur le marché touristique. Québec séduit de multiples façons mais essentiellement pour $\propto$ qu'elle est profondément, dans ses saisons comme dans ses habitants. Les témoignages qui suivent diront différemment ce qu'est Québec.

PierreMorency, néà Lauzon, prèsdeQuébec, dans un remarquable ouvrage intitulé Lumière des oiseaux, dit de Québec:

*[...] Québec une ville où la nature est partout présente. Tournez sur la rose des vents, vous verrez quelque part les montagnes, le fleuve, des caps, des îles, des bois.»

Le regretté Roger Lemelin, fils et amant de Québec, écrivait pour la revue Forces, il y a quelques années:

«[...] C'est un milieu complet, comme indépendant du reste du monde. C'est en ce sens que Québecest une ville absolue. Elle se dit canadienne par gentillesse envers les envahisseursde tout acabit dontelle supporte les séjours: les Françaisd'avant la Conquête, les Anglais d'après la Conquête et les autres Canadiensd'après 1867. [...] Cephénomène de rejet ou d'assimilation dans un écrasant continent anglo-saxon est mystérieux. Québec, comme Paris, Florence, Athènes, Vienne, a les entrailles embrasées par une flamme humaniste inextinguible, vieille de cinq mille ans. Que cette flamme-là soit celle du génie français est une décision des dieux.»

Que dire de plus? Que dire de mieux? $f$ 